\title{
A Coupled Density Functional Theory-Microkinetic Modeling for the Hydrodeoxygenation of Glycerol to Propylene on $\mathrm{MoO}_{3}$
}

\author{
Marcos Rellán-Piñeiro ${ }^{\circledR}$ and Núria López*® \\ Institute of Chemical Research of Catalonia (ICIQ), The Barcelona Institute of Science and Technology, Avinguda Països Catalans \\ 16, 43007 Tarragona, Spain
}

Supporting Information

\begin{abstract}
The production of propylene from renewable resources might be relevant to provide this compound in a scenario of scarcity due to the use of shale gas as a raw material. In the present, work we provide a full density functional theory description of the reaction network that drives the hydrodeoxygenation of glycerol on molybdenum oxide. From these results, a microkinetic model is built that allows the analysis of the most common routes and the potential bottlenecks compromising the activity and selectivity of the process. With this integrated scheme, we have found that the reaction proceeds mainly through the formation of hydroxypropanal, propanal, and 1-propanol, and the reaction order for hydrogen is close to 1 . Our work paves the way toward the evaluation of complex reaction networks for the study of biomass compounds.
\end{abstract}

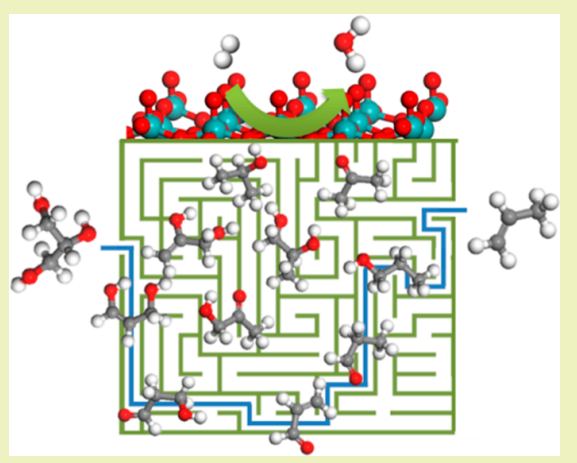

KEYWORDS: Density functional theory, Hydrodeoxygenation, Molybdenum oxide, Selectivity, Propylene

\section{INTRODUCTION}

The search of new renewable resources for key chemical intermediates is a direct consequence of the depletion of oil resources and the rising environmental concerns. Biomass has emerged as an alternative renewable feedstock, ${ }^{1}$ and initiatives to convert nonedible fractions and waste into chemical platforms are being explored. ${ }^{2,3}$ However, biomass is a complex raw material that includes a wide range of oxygenates as alcohols, aldehydes, ketones, carboxylic acids, and phenols. ${ }^{4}$ Due to the high oxygen content, the preferential $\mathrm{C}-\mathrm{O}$ bond cleavage over the other bonds $\mathrm{C}-\mathrm{C}$ and $\mathrm{C}-\mathrm{H}$ is a must to develop platform chemicals. In this direction, one of the most appealing processes to reduce the oxygen content is hydrodeoxygenation (HDO),${ }^{5-7}$ which achieves the reduction of the oxygen content in biomass-derived molecules by its reaction with $\mathrm{H}_{2}$ at high temperatures, producing water as a side product. Consequently, HDO is a clean process that allows obtaining key chemical intermediates from biomass-derived compounds.

Potential HDO catalysts include noble (Pd, Pt, Ru, Ag, and $\mathrm{Rh})^{8-14}$ and non-noble metals $(\mathrm{Cu}$ and $\mathrm{Ni}),{ }^{15,16}$ molybdenum sulfides, and carbides. ${ }^{17-19}$ More recently, metal oxides have also been proposed. For instance, molybdenum oxides showed good selectivity in HDO of alcohols, ${ }^{20-22}$ linear ketones, and cyclic ethers to produce olefins, and cyclic ketones and phenols to form aromatic hydrocarbons. ${ }^{23,24}$ In these reactions, $\mathrm{MoO}_{3}$ selectively breaks the $\mathrm{C}-\mathrm{O}$ bonds leading to the formation of hydrocarbons and olefins while keeping the carbon chain.

Among the biomass derivatives, glycerol plays a major role since it is a byproduct in the transesterification of vegetal oils that provides biodiesel. ${ }^{25}$ Around 10 tonnes of glycerol are produced per 100 tonnes of biodiesel. ${ }^{26}$ Thus, as a side product in biodiesel synthesis, glycerol is an abundant compound, ${ }^{27}$ and finding new efficient and environmentally friendly routes to upgrade it is a challenging industrial target. $^{28-33}$ Therefore, it was included as one of the top 12 building blocks by the DOE. ${ }^{34,35}$ The deoxygenation of glycerol can be a source for propanediols and propanols and more interestingly propylene, the starting compound for the production of polypropylene, acrylonitrile, propylene oxide, oxo alcohols, cumene, isopropyl alcohol, and others. ${ }^{36}$ The current propylene production is around 90 million tonnes, and it is forecasted to grow up to 130 million tonnes worldwide by $2023 .^{37}$ Nowadays, it is mainly obtained as a byproduct in naphtha steam cracking, ${ }^{36}$ but the emergence of shale-gas feedstocks will likely produce a shortage in the next years in localized geographical areas, mainly in the U.S. ${ }^{38}$ Therefore, an on-purpose technology for propylene production is an attractive industrial target, and its production from glycerol remains a promising route.

Glycerol conversion to propylene in a two-step system was reported. $\mathrm{Ir} / \mathrm{ZrO}_{2}$ catalyzed the glycerol hydrogenolysis to 1 propanol, which in a second step is dehydrated to propylene by H-ZSM-5. ${ }^{39}$ The conversion in one step catalyzed by molybdenum oxide, $\mathrm{Mo} / \mathrm{C}$, and iron molybdate, $\mathrm{Fe}-\mathrm{Mo} / \mathrm{C}$, was reported in both gas ${ }^{40,41}$ and liquid phases. ${ }^{42,43}$ The conversion in gas phase can reach $100 \%$ with $90 \%$ selectivity. 
The reaction pathway was studied, and the route through acetol, propylene glycol, acetone, and 2-propanol was proposed. ${ }^{41}$ In the liquid phase, the reported conversion on Mo/C was $70 \%$ with $70 \%$ selectivity. The main byproducts were C3 compounds: 2-propenol, 1-propanol, and propylene glycol. 2-Propanol, acetol, and 1,2-propanediol were also detected. A small portion, 2.5\%, of C2 and C1 compounds were also obtained: methanol, ethanol, and ethylene glycol. The reaction pathway studies suggested propylene is formed via 2-propenol, with 1- and 2-propanol dehydration as secondary routes. ${ }^{43}$ In addition, they found that the catalytic sites are the reduced surface Mo centers. Thus, the presence of surface oxygen vacancies is essential to reach high activity and selectivity to HDO.

The rationalization of HDO processes needs first-principle studies, but only a small number have been reported. The mechanism of alcohol dehydration ${ }^{20,21}$ and HDO of acrolein to propylene ${ }^{44}$ were studied on $\left(\mathrm{MoO}_{3}\right)_{3}$ cluster models, which cannot reproduce the bulk electronic and geometrical structure; thus, the robustness of the computed kinetic and thermodynamic parameters is unclear. Moreover, two studies were performed on $\alpha-\mathrm{MoO}_{3}(010)$ using periodic slabs: the HDO of acetaldehyde ${ }^{45}$ and acetone. ${ }^{46}$ The vacancy formation and the HDO mechanism were reported in both studies. They were performed with pure density functional theory (DFT), which tends to the overdelocalization of $d$ and $f$ electrons of reducible transition metal oxides (RTMOs) due to the selfinteraction error (SIE). ${ }^{47,48}$ This error results in incorrect estimations of reaction energies and activation barriers for redox steps in $\mathrm{HDO}$ processes and in the impossibility to characterize correctly the oxygen vacancies. ${ }^{49,50}$ In addition, $\mathrm{HDO}$ processes are formed by large reaction networks that require microkinetic models to be understood. These models are effective to obtain main reaction paths, rate-determining step (RDS), reaction orders, and more parameters from intricate reaction networks. However, their main drawback is that the energy barriers of each elementary step should be known, which is not possible from experiments. This problem can be solved by DFT, which most of the time offers a reasonable agreement with experiments. On the other hand, complex reaction networks are difficult to understand only from DFT reaction profiles, and its coupling with microkinetic models establishes a link between the simulations and the experimental observables giving a more powerful understanding of the system.

In this work, density functional theory has been employed to unravel the mechanism for the conversion of glycerol to propylene on models representing molybdenum oxide. As the number of intermediates and connectivity of the reaction network are very high, a microkinetic model was developed and applied to obtain the most likely reaction path and how the activity and selectivity of the catalyst proceeds.

\section{THEORETICAL METHODS}

DFT. Density functional theory (DFT) performed on slabs models with the VASP 5.3.3 package $^{51,52}$ were employed to obtain the thermodynamic and kinetic parameters for the HDO reaction network. The generalized gradient approximation (GGA) in the form of the Perdew-Burke-Ernzerhof (PBE) functional ${ }^{53}$ was chosen to describe the exchange correlation energy coupled to the van der Waals contributions from the Grimme's semiempiric correction vdW-D2. ${ }^{54}$ The core electrons were replaced by the projector-augmented wave (PAW) pseudopotentials, ${ }^{55}$ whereas valence electrons were expanded in plane waves with a kinetic cutoff energy of $450 \mathrm{eV}$. The Hubbard $\mathrm{U}^{56}$ correction was applied to describe the $4 \mathrm{~d}$ electrons of molybdenum atoms with $\mathrm{U}_{\text {eff }}=3.5 \mathrm{eV}^{50}$ Solvent contributions in adsorption energies were introduced through the VASP-MGCM ${ }^{57,58}$ code considering water as the solvent.

$\alpha-\mathrm{MoO}_{3}$ is the most common and stable phase of $\mathrm{MoO}_{3}$, which presents an orthorhombic unit cell with Pbnm symmetry. ${ }^{59}$ This structure is formed by bilayers of $\mathrm{MoO}_{6}$-distorted octhaedra packed through van der Waals contributions along the $y$-axis. The calculated lattice parameters with a $11 \times 3 \times 11 \mathrm{k}$-point mesh were found to be a $=3.933, \mathrm{~b}=13.822$, and $\mathrm{c}=3.711 \AA$, in agreement with experimental values. ${ }^{59,60}$ The HDO process was studied on the lowest energy facet of $\alpha-\mathrm{MoO}_{3}$, the (010) surface, Figure 1, which presents three oxygen
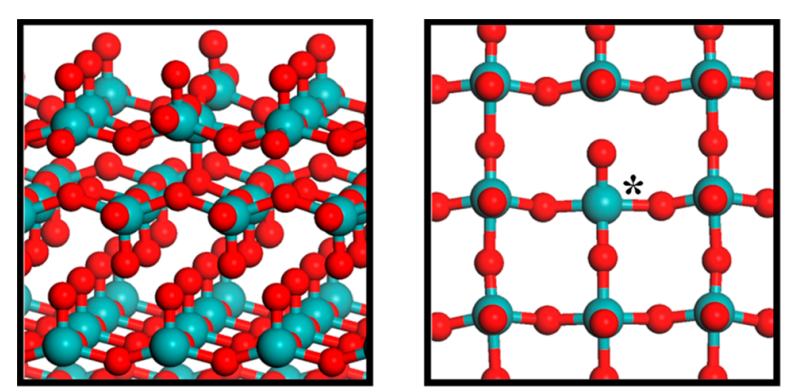

Figure 1. Side and top views of the reduced $\alpha-\mathrm{MoO}_{3}(010)$ surface used as catalyst. The reduced Mo center, $\mathrm{Mo}_{\text {cus }}$ is marked with $*$. Green spheres represent Mo and red stand for O.

types: (i) terminal oxygen, $\mathrm{O}_{\mathrm{t}}$, (ii) the oxygen bridge, $\mathrm{O}_{\mathrm{b}}$, and (iii) $\mathrm{O}_{3 c}$, coordinated to one, two, and three molybdenum atoms, respectively. $\mathrm{O}_{3 \mathrm{c}}$ can be considered inert. This surface model was previously used to study oxidation of methanol to formaldehyde ${ }^{61,62}$ and the HDO of acetaldehyde ${ }^{45}$ and acetone. ${ }^{46}$ The fully oxidized surface can only perform acid-base reactions, but the HDO process involves redox steps. Therefore, a reduced Mo center is needed for the reaction to occur. ${ }^{23}$ Molybdenum oxides accommodate a certain degree of reduction, and out of the oxygens in the lattice, the terminal ones $\mathrm{O}_{t}$ are the easiest to remove. ${ }^{43,50,63,64}$ The created vacancy positions are the preferential adsorption sites for oxygenated intermediates.

The $\alpha-\mathrm{MoO}_{3}(010)$ surface was represented with a slab model containing two bilayers in a $(3 \times 3)$ supercell with a $3 \times 3 \times 1$ k-point sampling. The upper bilayer and the adsorbates were allowed to relax. A vacuum of $15 \AA$ between slabs was introduced, and a dipole correction along the $z$-axis was added to avoid the spurious terms arising from the use of asymmetric arrangement of the slabs. ${ }^{65}$ The reaction network was studied in this slab model with one $\mathrm{O}_{t}$ vacancy simulating the surface reduction, Figure 1 ; the corresponding undercoordinated molybdenum center is labeled as $\mathrm{Mo}_{\text {cus. }}$. The transition states were located with the climbing image version of the nudge elastic band (CI-NEB) $)^{66,67}$ method and refined with the improved dimer method (IDM). ${ }^{68,69}$ All relevant configurations in the potential energy surface were confirmed through vibrational analysis, and the reported energies are ZPVE corrected. The relevant structures are published in the ioChem-BD database ${ }^{70}$ and can be found in ref 71.

Microkinetic Modeling. A batch reactor model was employed in the simulations. For each species, we expressed mathematically the variation of pressure (for gas compounds) or coverage (for adsorbates) as the sum of the rate of all elementary steps in the reaction network in which the species is involved. Each intermediate is considered to occupy only one site and a simple site balance is employed, $\theta_{*}=1-\Sigma \theta_{i}$. This set of equations forms an ordinary differential equation (ODE) system. The kinetic coefficient for adsorption/desorption steps is obtained from the Knudsen equation:

$$
r_{a d s, A}=k_{a d s, A} P_{A} \theta_{*}
$$




$$
k_{a d s, A}=\frac{A_{c a t}}{\sqrt{2 \pi m_{A} k_{B} T}} S_{0}(T)
$$

In these equations $P_{A}$ is the pressure of $\mathrm{A}$ in the reaction system; $\theta_{*}$ represents the fraction of free sites on the surface; $A_{\text {cat }}$ is the area of a free site; $m_{A}$ is the mass of a single molecule A; $k_{B}$ is the Boltzmann's constant; $T$ is the temperature of the reaction system; and $S_{0}(T)$ is the sticking coefficient, which is approximated by the exponential term, $e^{-E_{a, a d s} / k_{B} T}$. Equivalent equations were employed for desorption. The adsorption/desorption energies are those corrected by solvation. In turn, the rate for each on-surface elementary step follows the transition state theory (TST): ${ }^{72-74}$

$$
\begin{aligned}
& r_{A^{*} \rightarrow B^{*}}=k_{A^{*} \rightarrow B^{*}}^{+} \theta_{A^{*}} \\
& k_{A^{*} \rightarrow B^{*}}^{+}=\frac{k_{B} T}{h} \frac{q^{T S}}{q_{A^{*}}} e^{-E_{a}^{+} / k_{B} T}
\end{aligned}
$$

In these equations, $q_{A}$ and $q^{T S}$ are the vibrational contributions to the partition function of the initial and transition states, respectively, and $E_{a}$ is the ZPVE-corrected energy difference between the transition state and the initial state as obtained by DFT. Finally, initial conditions correspond to those of the experiments (batch reactor of $450 \mathrm{~mL}$, ca. $1.5 \mathrm{~g}$ of catalyst, $90 \mathrm{~mL}$ of $2.0 \mathrm{w} / \mathrm{w} \%$ aqueous glycerol solution, 8.0 MPa of $\mathrm{H}_{2}$, and $\left.300{ }^{\circ} \mathrm{C}\right),{ }^{42}$ and the number of initial vacancies was chosen to mimic the fraction of reduced centers described for the reduction of the catalyst at $350{ }^{\circ} \mathrm{C}$. XPS at this temperature shows $2.1 \%$ and $29.0 \%$ of $\mathrm{Mo}^{4+}$ and $\mathrm{Mo}^{5+} ;{ }^{43}$ and considering that there is only a single oxygen vacancy for every two $\mathrm{Mo}^{5+50}$ the number of initial vacancies was set to $15 \%$. The ODE system was solved numerically with Maple 13.0 software. $^{75}$

\section{RESULTS AND DISCUSION}

HDO processes are composed by two combined cycles: (i) the hydrogen adsorption and vacancy formation through water formation and release and (ii) adsorption and deoxygenation of hydrocarbonated compounds on a vacancy position. The second one heals the vacancy and closes the catalytic cycle. This catalytic procedure corresponds to a reverse Mars van Krevelen mechanism. Experimentally, a prereduction of the catalyst with $\mathrm{H}_{2}$ is carried out to form defects on the surface. $^{23,41,42}$ Moreover, it was shown that the presence $\mathrm{H}_{2}$ in the reaction media during the process is essential to maintain the catalytic activity. ${ }^{23,42}$

Vacancy Formation and Hydrogen Diffusion. Hydrogen molecules dissociatively adsorb forming two $-\mathrm{OH}$ groups that can be either two terminal $-\mathrm{O}_{\mathrm{t}} \mathrm{H}$ groups, with an energy barrier for the adsorption of $1.63 \mathrm{eV}$, or one $-\mathrm{O}_{\mathrm{t}} \mathrm{H}$ and one $-\mathrm{O}_{\mathrm{b}} \mathrm{H}$ group, with an energy barrier of $1.46 \mathrm{eV}$ (Table 1). These high energy barriers are due to the fact that adsorption takes place through a homolytic $\mathrm{H}-\mathrm{H}$ bond breaking without previous activation by the surface. This explains the strong dependence between the $\mathrm{H}_{2}$ pressure and the catalytic performance, which results in the large $\mathrm{H}_{2}$ pressure required

Table 1. Adsorption Energies, $E_{\text {ads }}$ in $\mathrm{eV}$, and Energy Barriers, $E_{\mathrm{a}}$ in $\mathrm{eV}$, of $\mathrm{H}_{2}$ Adsorption and Diffusion, Using as Reference a Clean Surface and Gas-Phase $\mathrm{H}_{2}$ Molecule

\begin{tabular}{ccccc}
\multicolumn{2}{c}{ Adsorption } & & & Diffusion \\
\cline { 1 - 2 } Site & $\mathrm{E}_{\mathrm{ads}}$ & & Path & $\mathrm{E}_{\mathrm{a}}$ \\
$\mathrm{O}_{\mathrm{t}} \mathrm{H}+\mathrm{O}_{\mathrm{t}} \mathrm{H}$ & -0.60 & & $\mathrm{O}_{\mathrm{t}} \mathrm{H}(\mathrm{a}) \rightarrow \mathrm{O}_{\mathrm{t}} \mathrm{H}(\mathrm{b})$ & 0.40 \\
$\mathrm{O}_{\mathrm{t}} \mathrm{H}+\mathrm{O}_{\mathrm{b}} \mathrm{H}$ & -0.69 & & $\mathrm{O}_{\mathrm{b}} \mathrm{H} \rightarrow \mathrm{O}_{\mathrm{t}} \mathrm{H}$ & 0.77 \\
$\mathrm{H}_{2} \mathrm{O}_{\mathrm{t}}$ & -0.92 & & $2 \mathrm{O}_{\mathrm{t}} \mathrm{H} \rightarrow \mathrm{H}_{2} \mathrm{O}_{\mathrm{t}}$ & 0.14 \\
$\mathrm{~V}_{\mathrm{Ot}}$ & 0.30 & & $\mathrm{O}_{\mathrm{b}} \mathrm{H}+\mathrm{O}_{\mathrm{t}} \mathrm{H} \rightarrow \mathrm{H}_{2} \mathrm{O}_{\mathrm{t}}$ & 0.22
\end{tabular}

in experiments to obtain high activity and selectivity. ${ }^{42,43}$ The adsorption energies for the two configurations are -0.60 and $-0.69 \mathrm{eV}$, respectively. Once the $-\mathrm{OH}$ groups are created, the hydrogen atoms can be transferred from a hydroxyl group to a neighboring surface oxygen and diffuse over the surface with relatively low energy barriers, ca. $\sim 0.4-0.8 \mathrm{eV}$ (Table 1 ).

The formation of water molecules by the recombination of two neighboring $-\mathrm{OH}$ groups has low energy barriers: 0.14 and $0.22 \mathrm{eV}$ from two $-\mathrm{O}_{\mathrm{t}} \mathrm{H}$ and from $-\mathrm{O}_{\mathrm{t}} \mathrm{H}+-\mathrm{O}_{\mathrm{b}} \mathrm{H}$, respectively. Thus, $\mathrm{H}_{2} \mathrm{O}_{t}$ molecules binding to the Mo center are formed at the catalyst surface. The energy required for water molecules to desorb is $1.22 \mathrm{eV}$, and therefore, they are released under reaction conditions. The reaction energy for the total process of vacancy formation is only $0.30 \mathrm{eV}$, being the adsorption of hydrogen the most energy-demanding steps (Scheme S1 and Figure S1).

Hydrodeoxygenation (HDO) Network. The glycerol HDO process encompasses the competition between sequential and parallel dehydrations, keto-enol equilibria, and hydrogenations reactions that are grouped in the reaction network presented in Scheme 1. The general mechanisms for each process are shown in Scheme 2.

Scheme 1. Reaction Network for the Complete Hydrodeoxygenation, HDO, of Glycerol to Propylene ${ }^{a}$

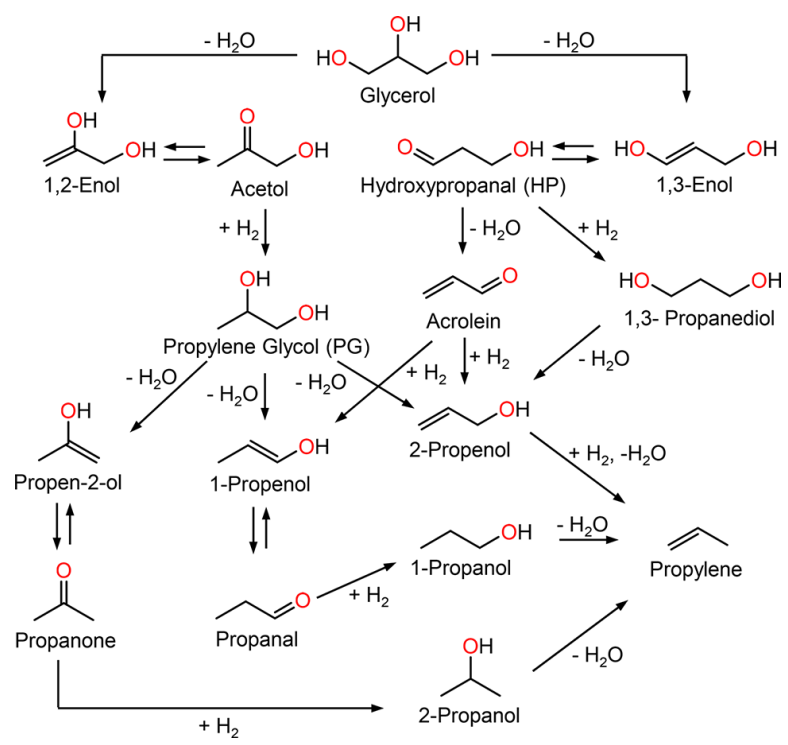

${ }^{a}$ Double arrows indicate keto-enolic equilibria.

The first step in HDO is glycerol dehydration to form the corresponding alkenol. The mechanism proposed previously for the dehydration of alcohols on molybdenum oxides, ${ }^{21}$ Scheme 2a, was followed. Glycerol adsorbs on a vacancy through one of its oxygens forming a $\mathrm{Mo}-\mathrm{O}$ bond. After that, the hydroxyl proton is transferred to a terminal oxygen forming an $-\mathrm{O}_{\mathrm{t}} \mathrm{H}$ group. Then, in a concerted step, a $\beta$-hydrogen is stripped away by $\mathrm{O}_{b}$, and concomitantly, the $\mathrm{C}-\mathrm{O}$ bond breaks (Figure S2a). The imaginary frequency of the transition state corresponds mainly to the $\mathrm{C}-\mathrm{H}$ bond breaking, being the concomitant $\mathrm{C}-\mathrm{O}$ bond breaking barrierless and unavoidable. This concerted step involves the formation of the $\mathrm{C}=\mathrm{C}$ double bond of the alkenol and the $\mathrm{Mo}=\mathrm{O}_{\mathrm{t}}$ bond on the surface. 
Scheme 2. Reaction Mechanism of Reactions in the Reaction Network: (a) Dehydration, (b) Keto-Enol Equilibrium, (c) Hydrogenation, and (d) 2-Propenol Conversion to Propylene ${ }^{a}$

a)

b)
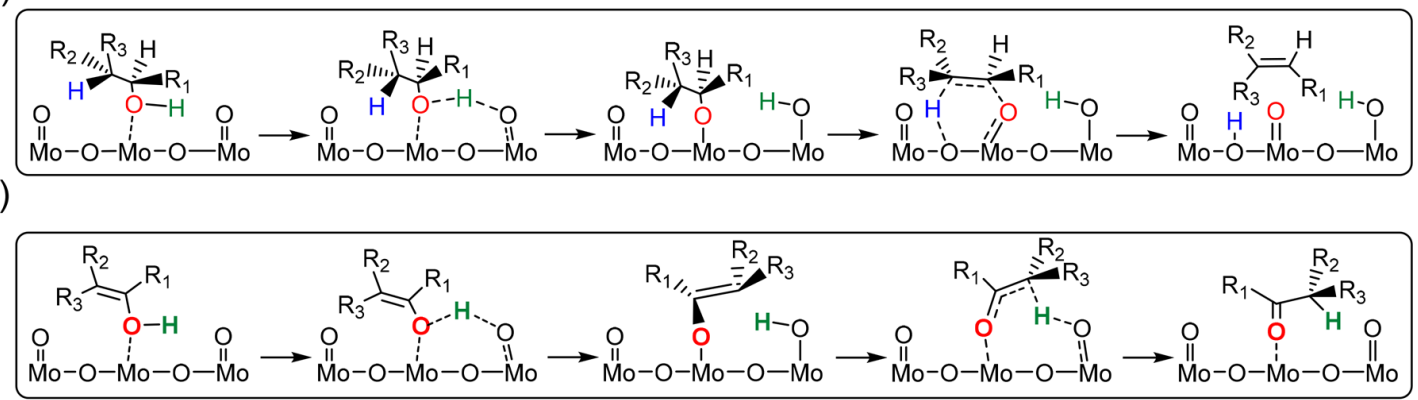

C)

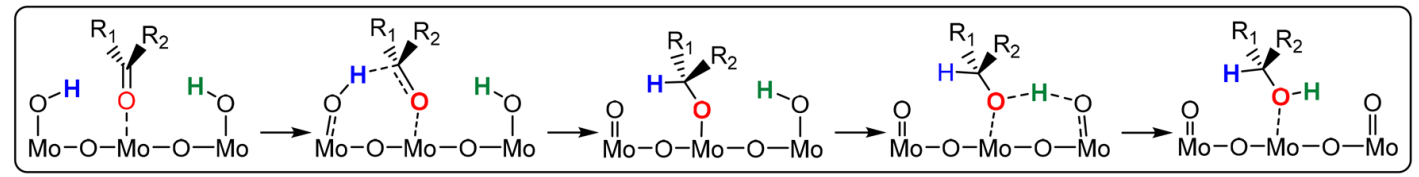

d)

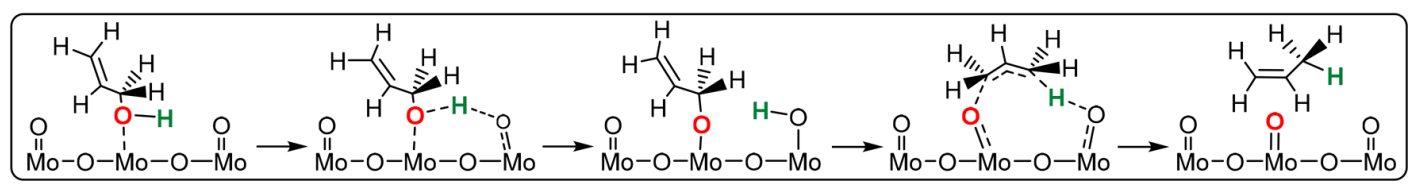

${ }^{a}$ Detailed schemes of each reaction of the HDO network are shown in Schemes S2-S5.

As glycerol has two different $-\mathrm{OH}$ types, adsorption by the terminal $-\mathrm{OH}$ triggers the formation of 1,2-enol, whereas the secondary hydroxyl would drive the formation of 1,3-enol. The enolates formed are in equilibrium with their keto tautomers, acetol and hydroxypropanal (HP), respectively. These equilibria, in aqueous phase, are thermodynamic displaced to the keto form by $-0.65 \mathrm{eV}$ to acetol and $-0.29 \mathrm{eV}$ to HP. The mechanism of the keto-enol interconversion is shown in Scheme $2 \mathrm{~b}$. The first elementary step in the tautomeric isomerization is the enolate adsorption on a vacancy position. They adsorb through their enolic $-\mathrm{OH}$ group that interacts with the $\mathrm{Mo}_{\text {cus }}$ center. Then, the $-\mathrm{OH}$ group dissociates transferring a hydrogen atom to an $\mathrm{O}_{\mathrm{t}}$. Finally, the hydrogen of the $-\mathrm{O}_{\mathrm{t}} \mathrm{H}$ group is transferred either to the methylene group $\left(\mathrm{H}_{2} \mathrm{C}=\right.$ ) of 1,2-enol to form acetol (Figure S2b) or to the methine group ( $=\mathrm{CH}-$ ) of 1,3-enol to form HP. Thereafter, the ketones can either desorb or remain bonded to the vacancy to react further.

In the next step, acetol and HP are hydrogenated to form propylene glycol (PG) and 1,3-propanediol, respectively. The general mechanismof hydrogenations is shown in Scheme $2 \mathrm{c}$. Acetol and $\mathrm{HP}$ adsorb on the $\mathrm{Mo}_{\text {cus }}$ site through the ketone group, and a hydrogen atom is transferred from a neighboring $-\mathrm{O}_{\mathrm{t}} \mathrm{H}$ group to the carbon atom of the ketone group to form a deprotonated diol. These diols could be protonated by other surface hydroxyls and desorb or experiment with further dehydration (Figure SI2c). In parallel, HP could suffer a new dehydration to form acrolein repeating the steps described previously. This is not possible for acetol because its $-\mathrm{OH}$ group does not have any $\beta$-hydrogens left to be stripped off.

Interaction of PG and 1,3-propanediol with $\mathrm{Mo}_{\text {cus }}$ can result in further dehydrations. PG adsorption through its primary hydroxyl group leads the dehydration to propen-2-ol, whereas through the secondary hydroxyl results in the dehydration to either 1-propenol, when the $\beta$-hydrogen of $\mathrm{C} 1$ is transferred to the surface, or 2-propenol, when $\beta$-hydrogen of $\mathrm{C} 3$ is stripped off. 1,3-Propanediol dehydration only can result in 2-propenol. Acrolein is hydrogenated either at the ketonic carbon to form 2-propenol, like 1,3-propanediol, or at the methylene carbon to form 1-propenol. Propen-2-ol and 1-propenol are enolates, and therefore, they are in equilibrium with the corresponding keto tautomer, propanone and propanal, respectively, which are more stable than the corresponding enol formed by -0.60 and $-0.35 \mathrm{eV}$, respectively.

In turn, propanone and propanal adsorbed at $\mathrm{Mo}_{\text {cus }}$ are hydrogenated to 2-propanol and 1-propanol, respectively. These two compounds are dehydrated on the vacancy position to form the final product: propylene. 2-Propenol adsorption on undercoordinated Mo also leads to propylene. Formally, this reaction encompasses the hydrogenation of the alkene and the dehydration of the alcohol group, but it follows a direct mechanism (Scheme 2d), and therefore, it cannot be included in any of the previous reaction families. The molecule adsorbs through the $-\mathrm{OH}$ group, which is dissociated by an $-\mathrm{O}_{\mathrm{t}}$ forming a surface hydroxyl. Then, hydrogen is transferred back from the surface hydroxyl to the methylene group $\left(\mathrm{H}_{2} \mathrm{C}=\right)$ of the adsorbed 2-propenol at the same time that $\mathrm{C}-\mathrm{O}$ bond breaks, resulting in propylene physisorbed on the surface. A similar mechanism to the formation of propylene from 2propenol on a $\mathrm{Mo}_{3} \mathrm{O}_{9}$ cluster has been proposed previously. $^{11,43,44}$

Reaction and activation energies for each elemental reaction step in glycerol HDO are shown in Figure 2. More detailed values are in Table SI1. An analysis of the data shows that alcohol deprotonations are always endothermic steps with energy barriers lower than $0.75 \mathrm{eV}$. The $\mathrm{C}-\mathrm{O}$ bond breaking 


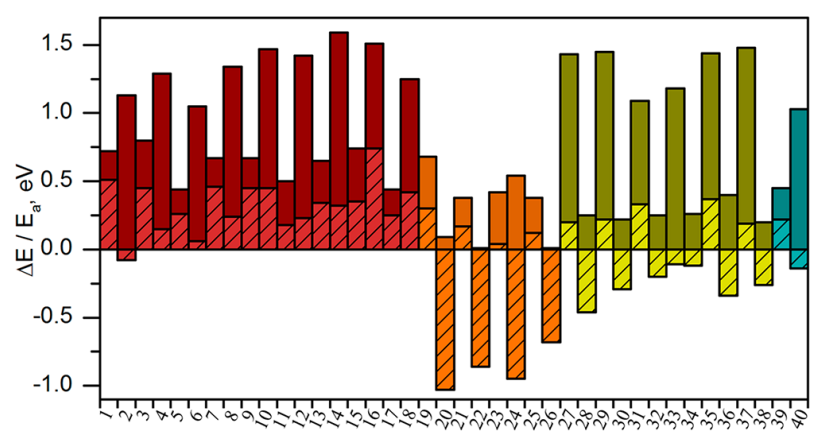

Figure 2. Reaction energy, $\Delta E$ (striped bars), and activation energy, $E_{\mathrm{a}}$ (plain bars), for all direct elementary steps of the reaction network. Wine color corresponding to dehydrations, orange to keto-enol equilibrium, yellow to hydrogenations, and turquois to the 2propenol-propylene reaction. All energies are in $\mathrm{eV}$. The specific reactions are listed in Table S2.

steps in dehydrations are slightly endothermic with high energy barriers, between 1.00 and $1.50 \mathrm{eV}$, being favored for the removal of primary $-\mathrm{OH}$ groups over the secondary ones. In these steps, the energy barrier is generated by the $\mathrm{C}-\mathrm{H}$ bond breaking, with the concomitant $\mathrm{C}-\mathrm{O}$ bond cleavage barrierless. The formation of $\mathrm{C}-\mathrm{H}$ bonds in keto-enol equilibria are highly exothermic steps with a very low energy barrier; the tautomerism has lower energy barriers when the enol group is in a primary carbon. Finally, the hydrogenations of ketones are slightly endothermic steps with similar energy barriers as $\mathrm{C}-\mathrm{O}$ bond breaking, which are independent of the position of the ketone group. The reported experimental temperature is $300{ }^{\circ} \mathrm{C},{ }^{23}$ high enough to ensure that the barriers can be overcome.

$\mathrm{C}-\mathrm{C}$ Bond Cleavage. The fact that $\mathrm{C}-\mathrm{O}$ bond breaking prevails does not completely overrule $\mathrm{C}-\mathrm{C}$ bond cleavage. Indeed, some methanol, ethanol, and ethylene glycol (EG) were detected as minor reaction products, about $2.5 \%$ in total, for the reaction catalyzed on iron molybdate and molybdenum oxide catalyst. ${ }^{42,43}$ Ethylene glycol and ethanol could be produced from $\mathrm{C}-\mathrm{C}$ bond cleavage in glycerol and propylene glycol, respectively, which also gives methanol in both cases by the pathway showed in Scheme 3.

In the reactions proposed in Scheme 3, glycerol and PG have to be bonded to two neighboring $\mathrm{Mo}_{\text {cus }}$ through the two hydroxyl groups of the broken $\mathrm{C}-\mathrm{C}$ bond. The two reduced Mo act as electron buffers allowing the bond breaking. The formation of a neighboring vacancy along the $z$-axis has no extra formation energy, ${ }^{50}$ and therefore, they appear at

Scheme 3. Proposed C-C Bond Cleavage Reactions and Concomitant Formation of Methanol, Ethanol, and Ethylene Glycol $^{a}$

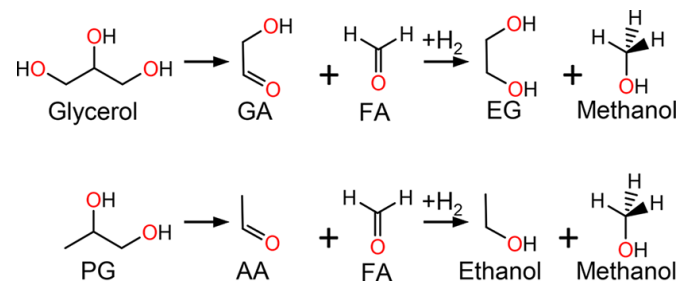

${ }^{a}$ GA: glycoaldehyde; FA: formaldehyde; PG: propylene glycol; AA: acetaldehyde. medium surface reductions. Then, glycerol and PG can adsorb directly to two undercoordinated $\left(\mathrm{Mo}_{\text {cus }}\right)_{2}$ centers through two $\mathrm{OH}$ groups. Once the molecules are adsorbed, they are dissociated easily forming two $-\mathrm{OH}_{\mathrm{t}}$ groups and two Mo-O covalent bonds with the surface. In this step, each $\mathrm{Mo}_{\text {cus }}$ is oneelectron oxidized. The adsorption energy for the dissociated molecules are -2.37 and $-2.43 \mathrm{eV}$ for glycerol and PG, respectively. The dissociated glycerol double bonded to $\left(\mathrm{Mo}_{\text {cus }}\right)_{2}$ can undergo the $\mathrm{C}-\mathrm{C}$ bond breaking that results in the formation of a ketone group in each fragment and the oneelectron reduction of the $\mathrm{Mo}_{\text {cus }}$ centers leading the formation of glycoaldehyde (GA) and formaldehyde. The energy barrier for this step is $1.66 \mathrm{eV}$. The same elementary step can occur for PG with an activation energy of $1.65 \mathrm{eV}$, resulting in the formation of formaldehyde (FA) again and acetaldehyde (AA). These compounds are further hydrogenated to methanol, EG, and ethylene.

The high energy barrier calculated for the $\mathrm{C}-\mathrm{C}$ bond cleavage and the necessity of two neighboring vacancies explain the selectivity to three-carbon products observed experimentally. In the reaction network, there are no more compounds with $-\mathrm{OH}$ groups in adjacent carbons, and therefore, these are the only possible one and two carbonformed products.

Microkinetic Model. The complexity of the reaction network makes it difficult to obtain a complete understanding and a direct mapping to the experimental activity of the HDO process of the glycerol conversion to propylene. Therefore, a microkinetic model ${ }^{76-78}$ was developed in order to know the product evolution during the glycerol HDO. The microkinetic model simulates the experimental conditions reported by Zacharapoulou et al.: a batch reactor of $450 \mathrm{~mL}$, ca. $1.5 \mathrm{~g}$ of catalyst that corresponds to $\sim 0.2 \mathrm{~g}$ of $\mathrm{MoO}_{3}$ and $\sim 1.3 \mathrm{~g}$ of activated carbon (in the experimental catalyst synthesis, $1.5 \mathrm{~g}$ of $\mathrm{MoO}_{3}$ is supported on $10 \mathrm{~g}$ of activated carbon), ${ }^{41} 90 \mathrm{~mL}$ of $2.0 \mathrm{w} / \mathrm{w} \%$ aqueous glycerol solution (1.8 g of glycerol), 8.0 $\mathrm{MPa}$ of $\mathrm{H}_{2}$, and $300{ }^{\circ} \mathrm{C}^{42,43}$ The $\mathrm{C}-\mathrm{C}$ bond breaking was excluded from the microkinetic model due to the low amount of $\mathrm{C} 2$ and $\mathrm{C} 1$ compounds formed in their experiments $(<2.5 \%)$. Moreover, propylene was not allowed to readsorb on the surface since they found that this compound leaves the liquid phase after reaction.

The selectivity evolution of the products and coverage of the different adsorbates for glycerol HDO as a function of time is shown in Figure 3. At the beginning of the reaction, acetol and HP are quickly formed. The adsorption energy of glycerol through the secondary $-\mathrm{OH}$ is larger than through the primary $-\mathrm{OH}$, and therefore, glycerol will be preferentially dehydrated to 1,3-enol. The fast keto-enol equilibria between 1,3-enol and HP leads a larger selectivity of $\mathrm{HP}$, which decreases quickly until the second hour. The high energy barrier for the first step of HP hydrogenation to 1,3-propanediol and the low amount of available $-\mathrm{O}_{\mathrm{t}} \mathrm{H}$ results in the dehydration of $\mathrm{HP}$ to acrolein, as can be retrieved for the coverage of adsorbed acrolein in this period. However, due to the large adsorption energy of acrolein, and to its easy hydrogenation to 1-propanol, acrolein reacts on the surface, and no selectivity to its production is obtained. In the first two hours, propanal selectivity is increasing, reaching almost $50 \%$ selectivity. The fast decrease in HP selectivity in this period, from $\sim 75 \%$ to $\sim 27 \%$, indicates that propanal is formed by HP dehydration to acrolein and later hydrogenation to 1-propenol, which is in a very favorable keto-enol equilibria with propanal. The coverage of acrolein 

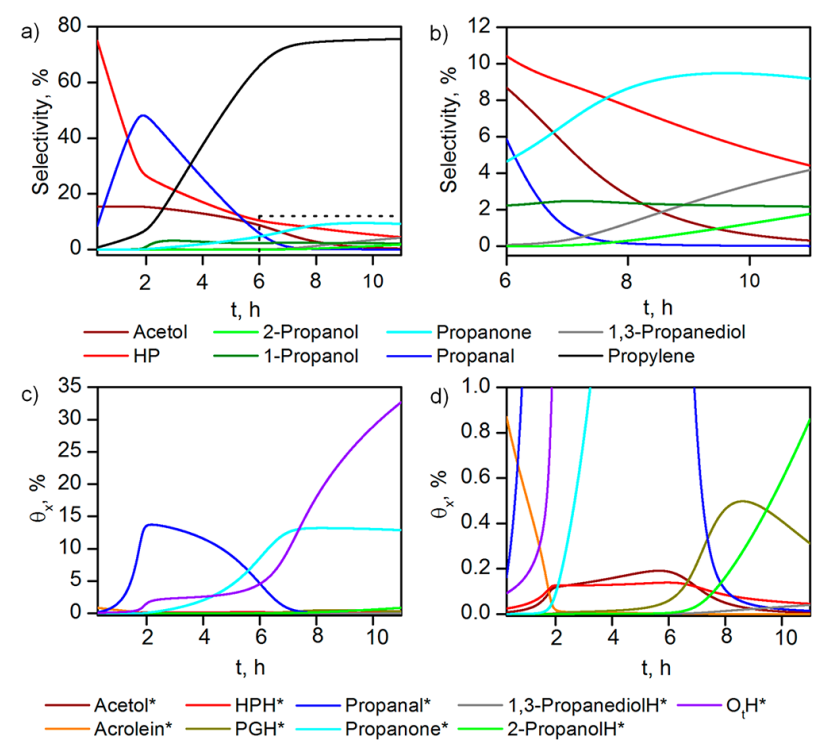

Figure 3. (a) Product selectivity evolution as a function of time, $t$ in hours, under the reaction conditions (batch reactor of $450 \mathrm{~mL}, 0.2 \mathrm{~g}$ of $\mathrm{MoO}_{3}, 1.8 \mathrm{~g}$ of glycerol, $8.0 \mathrm{MPa}$ of $\mathrm{H}_{2}$, and $300{ }^{\circ} \mathrm{C}$ ). (b) Zoomed area of the marked zone in (a). (c) Evolution of the coverage of adsorbed species, $\theta_{x}$, as a function of the time. (d) Zoomed area for coverage between $0 \%$ and $1 \%$ in (c). Intermediate products with negligible selectivity or coverage are not represented.

decreases slowly in this period, whereas the coverage of propanal increases rapidly. This is due to the fact that the formation of propanal is faster than the formation of acrolein, as the latter is an endothermic process that has higher energy barriers. Acrolein also can be hydrogenated to 2-propenol, which has low energy barriers to its conversion to propylene, which is slowly formed reaching $7 \%$ of selectivity in this period. During these two hours, the selectivity of acetol remains almost constant, around $16 \%$, due to the high energy barriers to its hydrogenation to $\mathrm{PG}$ and the low availability of $-\mathrm{O}_{\mathrm{t}} \mathrm{H}$ groups. The coverage of acetol increases slightly during this period indicating that acetol slowly adsorbs to react. After this point, propanal selectivity starts to decrease, whereas propylene selectivity increases quickly, which points out that propylene is formed from propanal through its hydrogenation to 1-propanol and later dehydration to propylene. The selectivity to 1propanol rises to $3 \%$ after $3.5 \mathrm{~h}$. This small selectivity to 1 propanol is due to the energy barriers because its dehydration to propylene is faster than propanal hydrogenation. The increase in coverage of $-\mathrm{O}_{\mathrm{t}} \mathrm{H}$ at this point supports the hydrogenation of propanal. After $2 \mathrm{~h}$, acetol also starts to hydrogenate to PG, and its selectivity slowly decreases. PG can be dehydrated to propen-2-ol, 1-propenol, or 2-propenol. The lowest energy barriers found for the formation of propen-2-ol, imply that it is rapidly isomerized to propanone. Thus, after this time, an increase in the coverage and selectivity of propanone is observed. After $6 \mathrm{~h}$, the propylene selectivity reaches $66 \%$, and the main byproducts are HP and acetol, $10.4 \%$ and $8.6 \%$ of selectivity, respectively. Propanal (5.9\%), propanone $(4.7 \%)$, and 1-propanol $(2.2 \%)$ are also formed. If the reaction time is extended, the coverage of $-\mathrm{O}_{\mathrm{t}} \mathrm{H}$ increases, constantly favoring acetol, HP, propanal, and propanone hydrogenation to their respective products: PG, 1,3-propanediol, 1-propanol, and 2-propanol. After $10 \mathrm{~h}$, low selectivity to these products appeared: $3.4 \%, 2.2 \%$, and $1.2 \%$ of 1,3 - propanediol, 1-propanol. and 2-propenol, respectively, whereas PG was not detected. However, the coverage of adsorbed PG increases during this period, but its fast conversion to propen2-ol prevents selectivity to this product. The propylene selectivity is almost constant after $8 \mathrm{~h}$ and reaches $75 \%$ after $10 \mathrm{~h}$.

A more detailed understanding of the reaction routes can be obtained starting the reaction with some of the intermediate products as initial reactant. The conversion and selectivity after $3 \mathrm{~h}$ of simulated reaction are shown in Figure 4 . After $3 \mathrm{~h}$,

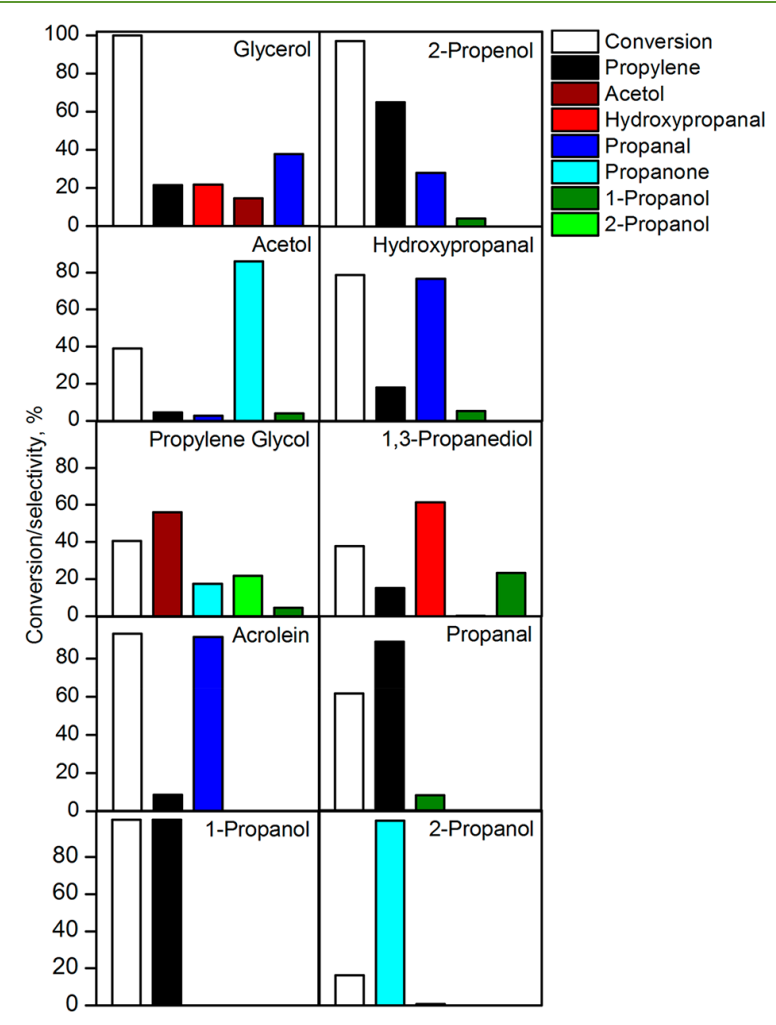

Figure 4. Conversion and selectivity at $3 \mathrm{~h}$ of simulated reaction on the microkinetic model of intermediate products as initial reactant under the experimental reaction conditions (batch reactor of $450 \mathrm{~mL}$, $0.2 \mathrm{~g}$ of $\mathrm{MoO}_{3}, 1.8 \mathrm{~g}$ of initial intermediate, 8.0 $\mathrm{MPa}$ of $\mathrm{H}_{2}$, and 300 $\left.{ }^{\circ} \mathrm{C}\right)$.

glycerol has $100 \%$ conversion. The main product is propanal $(\sim 34 \%)$ followed by HP $(\sim 22 \%)$, propylene $(\sim 22 \%)$, and acetol $(\sim 15 \%)$. Most of the glycerol reacts to form HP that is dehydrated and latter hydrogenated to form propanal. Some propanal and possibly some acetol are reduced to propylene. The use of 2-propenol as a reactant results in a complete conversion, mainly toward propylene $(\sim 67 \%)$. Propanal and 1 propanol, which are formed through acrolein, are also observed.

At the beginning of glycerol HDO, acetol and HP are formed with high selectivity. Using them as reactants, the larger conversion of HP ( $78 \%$ vs $39 \%$ ) indicates that it reacts faster than acetol. Propanal is the main product obtained from HP, with $77 \%$ selectivity. The other observed compounds were 1-propanol and propylene, which came from further reactions of propanal. On the other hand, acetol is mainly converted in propanone. 
Both diols, PG and 1,3-propanediol, as reactants show a low conversion $(\sim 40 \%)$. Most PG goes back in the reaction network toward acetol, with 56\% selectivity, and the rest of PG continues on the path to propylene, and small amounts of intermediates are formed. The reaction profile of 1,3propanediol shows that it also goes back toward HP ( $\sim 61 \%)$; moreover, some of the formed HP continues reacting toward the formation of 1-propanol and propylene. Interestingly, no 2-propenol is formed from 1,3-propanediol.

Acrolein as the reactant reaches $93 \%$ conversion. Almost all is converted to propanal ( $91 \%$ of selectivity). The $9 \%$ of propylene suggests that some propanal further reacted to form propylene. The conversion of propanal as the reactant is $\sim 63 \%$, with $91 \%$ selectivity to propylene. The other observed compound is the intermediate 1-propanol.

The two propanols show a completely different reaction profile; 1-propanol is completely converted to propylene (100\% of conversion and selectivity), whereas 2-propanol has only a $16 \%$ of conversion and only forms propanone.

With the insights obtained from the information in Figures 3 and 4, we can conclude that the glycerol conversion to propylene is produced through the following path: Glycerol $\rightarrow$ HP $\rightarrow$ Acrolein $\rightarrow$ Propanal $\rightarrow$ 1-Propanol $\rightarrow$ Propylene. There are three factors that lead the glycerol HDO for this reaction path: (i) The preference of glycerol adsorption is through the secondary carbon and conversion to 1,3-enol. (ii) The energy barriers for HP dehydration to acrolein are lower than for its hydrogenation to 1,3-propanediol. This is supported by the low availability of $-\mathrm{O}_{\mathrm{t}} \mathrm{H}$ groups. (iii) The first step in the formation of 1-propenol from acrolein is an exothermic process, whereas the formation of 2-propenol is endothermic, which favors the formation of the former.

Going back to the full reaction model, simulations at different temperatures were performed, and apparent activation energies of 1.38 and $2.03 \mathrm{eV}$ were obtained at 100 and $2500 \mathrm{~s}$ (Figure 5a). The apparent activation energy increases with reaction time since in a batch reactor the consumption of reactants decreases the reaction rate. Finally, in order to
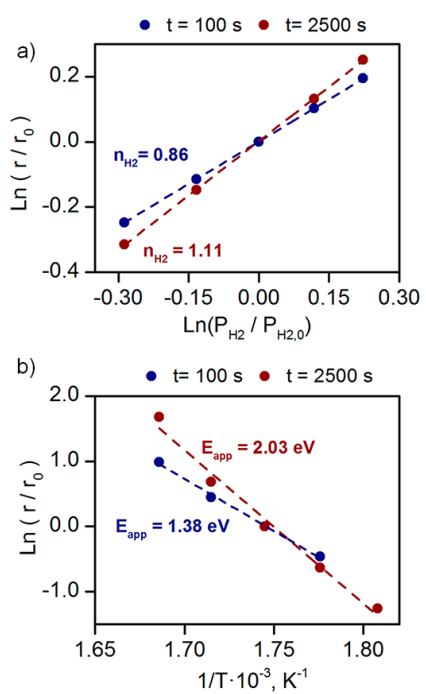

Figure 5. (a) Reaction order of hydrogen, $n_{H 2}$, derived from the microkinetic model at standard reaction conditionsand (b) Apparent activation energy, $E_{\text {app }}$ in $\mathrm{eV}$. Rates, $\mathrm{r}$, and $\mathrm{P}_{\mathrm{H} 2}$ are normalized to the value of the simulation at experimental conditions. identify the reaction orders, simulations with different initial pressures of hydrogen were performed. The reaction rate was measured at two different times, 100 and $2500 \mathrm{~s}$, and the reaction order was obtained, 0.86 and 1.11 , respectively (Figure $5 \mathrm{~b}$ ). This result highlights the importance of $\mathrm{H}_{2}$ in reaction media.

When compared to the experiments, there are some differences between our results and the previous from Zacharapoulou et al. ${ }^{42,43}$ The first difference is the conversion and reaction rate of glycerol; in our model, we obtained a faster conversion of glycerol due to nonconsideration of lateral effects and to perform the simulations in the gas phase. Although the final product distribution is in reasonable agreement, we want to highlight that in the experimental study PG and 2-propenol were detected as two of the main reaction intermediates. They are present in our reaction network, but they react rapidly and were not observed. Moreover, at the beginning of the reaction, we found higher amounts of acetol and HP, probably due to the faster conversion of glycerol observed in our model when compared to the experimental set up. Finally, the experiments suggests a reaction path through 2-propenol, whereas in our model the main path is through 1-propenol. Also, they discarded the route through acrolein because it was not detected in the experiments; however, we show that acrolein reacts quickly to form 1-propenol (and 2-propenol), which would explain the experimental results. The catalytic performance depends strongly on several factors as the reaction conditions or catalysts synthesis procedure. Thus, different results were reported by this reaction catalyzed by $\mathrm{Fe}-\mathrm{Mo} / \mathrm{C} .^{41,42}$ Different glycerol conversion, product distribution, and main reaction path were found. Moreover, the approximations that demand the state-of-the-art coupled DFT and microkinetic modeling (lateral effects, solvent models, etc.) and difficulty to take into account all the reaction parameters (structure sensitivity of the catalyst, solvent interactions) are also a source for these differences.

\section{CONCLUSIONS}

The glycerol conversion to formaldehyde catalyzed by $\alpha-\mathrm{MoO}_{3}$ was studied by means of density functional theory, DFT. The conversion is produced through a hydrodeoxygenation, HDO, process that takes place on surface vacancy defects. The highest energy barrier in the vacancy formation cycle is the hydrogen dissociative adsorption. This explains why high $\mathrm{H}_{2}$ pressure is needed in experiments. The adsorbed hydrogen atoms can move over the surface with low energy barriers to form water molecules that are released. Vacancies play a central role in the HDO process. Oxygenated compounds adsorb on the surface through $\mathrm{Mo}-\mathrm{O}$ bonds with an undercoordinated Mo center; after that, a selective $\mathrm{C}-\mathrm{O}$ bond cleavage produces the deoxygenated compound, while the oxygen atom remains bonded to the Mo center healing the vacancy. The complete HDO cycle is composed of three different sets of reactions: (i) dehydrations, (ii) keto-enol equilibria, and (iii) hydrogenations. The combination of these three reactions on vacancy positions results in a reaction network with 14 intermediates connected by 20 reactions where all the side products experimentally reported are present. The high reaction barrier for the $\mathrm{C}-\mathrm{C}$ bond cleavage and the necessity of two neighboring empty vacancies explain the selectivity to $\mathrm{C}-\mathrm{O}$ bond cleavage. The reaction mechanism unraveled in this work can be applied to the HDO of any polyalcohol. A 
microkinetic analysis of the reaction network was performed, and it was shown that glycerol conversion to propylene is mainly produced via the formation of HP, acrolein, propanal, and 1-propanol. A reaction order of 1 was calculated for $\mathrm{H}_{2}$, with apparent activation energies of 1.38 and $2.03 \mathrm{eV}$ at initial and medium times, respectively. The results shown in this study pave the way to a better understanding of the HDO process giving insights to development of a more active and selective catalyst.

\section{ASSOCIATED CONTENT}

\section{S Supporting Information}

ioChem-BD instructions, vacancy formation scheme and energy profile, reactions energy data, schemes, and optimized structures of reactions. (PDF)

\section{AUTHOR INFORMATION}

\section{Corresponding Author}

*E-mail:nlopez@iciq.es.

\section{ORCID $\odot$}

Marcos Rellán-Piñeiro: 0000-0002-7905-9077

Núria López: 0000-0001-9150-5941

\section{Funding}

Marcos Rellán-Piñeiro and Núria López received funding from Spanish Ministerio de Economía y Competitividad (MINECO): CTQ 2015-68770-R and Severo Ochoa Excellence Accreditation 2014-2018 SEV-2013-0319 Marcos RellánPiñeiro received funding from Spanish Ministerio de Economía y Competitividad (MINECO): Severo Ochoa predoctoral grant SVP-2014-068237.

\section{Notes}

The authors declare no competing financial interest.

\section{ACKNOWLEDGMENTS}

The authors acknowledge the Spanish Ministerio de Economía y Competitividad (MINECO) for financial support (CTQ 2015-68770-R, Severo Ochoa Excellence Accreditation 20142018 SEV-2013-0319 and Severo Ochoa predoctoral grant SVP-2014-068237). We thank BSC-RES for providing computational resources. In addition, we thank Dr. Rodrigo Garc-Muelas for valuable suggestions.

\section{REFERENCES}

(1) Huber, G. W.; Corma, A. Synergies between Bio- and Oil Refineries for the Production of Fuels from Biomass. Angew. Chem., Int. Ed. 2007, 46 (38), 7184-7201.

(2) Dapsens, P. Y.; Mondelli, C.; Pérez-Ramírez, J. Biobased Chemicals from Conception toward Industrial Reality: Lessons Learned and To Be Learned. ACS Catal. 2012, 2 (7), 1487-1499.

(3) Ruppert, A. M.; Weinberg, K.; Palkovits, R. Hydrogenolysis Goes Bio: From Carbohydrates and Sugar Alcohols to Platform Chemicals. Angew. Chem., Int. Ed. 2012, 51 (11), 2564-2601.

(4) Bridgwater, A. V. Review of Fast Pyrolysis of Biomass and Product Upgrading. Biomass Bioenergy 2012, 38, 68-94.

(5) Furimsky, E. Catalytic Hydrodeoxygenation. Appl. Catal., A 2000, 199 (2), 147-190.

(6) Saidi, M.; Samimi, F.; Karimipourfard, D.; Nimmanwudipong, T.; Gates, B. C.; Rahimpour, M. R. Upgrading of Lignin-derived BioOils by Catalytic Hydrodeoxygenation. Energy Environ. Sci. 2014, 7 (1), 103-129.
(7) Wang, H.; Male, J.; Wang, Y. Recent Advances in Hydrotreating of Pyrolysis Bio-Oil and Its Oxygen-Containing Model Compounds. ACS Catal. 2013, 3 (5), 1047-1070.

(8) Runnebaum, R. C.; Nimmanwudipong, T.; Block, D. E.; Gates, B. C. Catalytic Conversion of Compounds Representative of Ligninderived Bio-Oils: a Reaction Network for Guaiacol, Anisole, 4methylanisole, and Cyclohexanone Conversion Catalysed by $\mathrm{Pt} / \mathrm{a}-$ $\mathrm{Al}_{2} \mathrm{O}_{3}$. Catal. Sci. Technol. 2012, 2 (1), 113-118.

(9) Sitthisa, S.; Resasco, D. Hydrodeoxygenation of Furfural Over Supported Metal Catalysts: A Comparative Study of $\mathrm{Cu}, \mathrm{Pd}$ and Ni. Catal. Lett. 2011, 141 (6), 784-791.

(10) Gonzalez, C.; Marin, P.; Diez, F. V.; Ordonez, S. Hydrodeoxygenation of Acetophenone over Supported Precious Metal Catalysts at Mild Conditions: Process Optimization and Reaction Kinetics. Energy Fuels 2015, 29, 8208-8215.

(11) Ramos, R.; Tisler, Z.; Kikhtyanin, O.; Kubicka, D. Towards Understanding the Hydrodeoxygenation Pathways of FurfuralAcetone Aldol Condensation Products over Supported Pt Catalysts. Catal. Sci. Technol. 2016, 6, 1829-1841.

(12) Zhou, L.; Lawal, A. Hydrodeoxygenation of Microalgae Oil to Green Diesel over Pt, Rh and Presulfided NiMo Catalysts. Catal. Sci. Technol. 2016, 6, 1442-1454.

(13) Nelson, R. C.; Baek, B.; Ruiz, P.; Goundie, B.; Brooks, A.; Wheeler, M. C.; Frederick, B. G.; Grabow, L. C.; Austin, R. N. Experimental and Theoretical Insights into the Hydrogen-Efficient Direct Hydrodeoxygenation Mechanism of Phenol over $\mathrm{Ru} / \mathrm{TiO}_{2}$. ACS Catal. 2015, 5, 6509-6523.

(14) Lari, G. M.; García-Muelas, R.; Mondelli, C.; López, N.; PérezRamírez, J. Glycerol Oxidehydration to Pyruvaldehyde over Silverbased Catalysts for Improved Lactic Acid Production. Green Chem. 2016, 18 (17), 4682-4692.

(15) Witsuthammakul, A.; Sooknoi, T. Selective Hydrodeoxygenation of Bio-Oil Derived Products: Ketones to Olefins. Catal. Sci. Technol. 2015, 5, 3639-3648.

(16) Khromova, S. A.; Smirnov, A. A.; Bulavchenko, O. A.; Saraev, A. A.; Kaichev, V. V.; Reshetnikov, S. I.; Yakovlev, V. A. Anisole Hydrodeoxygenation over Ni-Cu Bimetallic Catalysts: The Effect of $\mathrm{Ni} / \mathrm{Cu}$ Ratio on Selectivity. Appl. Catal., A 2014, 470, 261-270.

(17) Popov, A.; Kondratieva, R.; Mariey, L.; Goupil, J. M.; El Fallah, J.; Gilson, J. P.; Travert, A.; Mauge, F. Bio-oil Hydrodeoxygenation and Adsorption of Phenolic Compounds on Sulfided (Co)Mo Catalysts. J. Catal. 2013, 297, 176-186.

(18) Wang, W.; Li, L.; Wu, K.; Zhu, G.; Tan, S.; Li, W.; Yang, Y. Hydrothermal Synthesis of Bimodal Mesoporous $\mathrm{MoS}_{2}$ Nanosheets and their Hydrodeoxygenation Properties. RSC Adv. 2015, 5, 6179961807.

(19) Chen, C.-J.; Lee, W.-S.; Bhan, A. $\mathrm{Mo}_{2} \mathrm{C}$ Catalyzed Vapor Phase Hydrodeoxygenation of Lignin-Derived Phenolic Compound Mixtures to Aromatics under Ambient Pressure. Appl. Catal., A 2016, 510, $42-48$.

(20) Li, Z.; Fang, Z.; Kelley, M. S.; Kay, B. D.; Rousseau, R.; Dohnalek, Z.; Dixon, D. A. Ethanol Conversion on Cyclic $\left(\mathrm{MO}_{3}\right)_{3}(\mathrm{M}$ = Mo, W) Clusters. J. Phys. Chem. C 2014, 118 (9), 4869-4877.

(21) Rousseau, R.; Dixon, D. A.; Kay, B. D.; Dohnalek, Z. Dehydration, Dehydrogenation, and Condensation of Alcohols on Supported Oxide Catalysts Based on Cyclic $\left(\mathrm{WO}_{3}\right)_{3}$ and $\left(\mathrm{MoO}_{3}\right)_{3}$ clusters. Chem. Soc. Rev. 2014, 43 (22), 7664-7680.

(22) Matsuda, T.; Hirata, Y.; Suga, S.; Sakagami, H.; Takahashi, N. Effect of $\mathrm{H}_{2}$ Reduction on the Catalytic Properties of Molybdenum Oxides for the Conversions of Heptane and 2-propanol. Appl. Catal., A 2000, 193 (1-2), 185-193.

(23) Prasomsri, T.; Nimmanwudipong, T.; Roman-Leshkov, Y. Effective Hydrodeoxygenation of Biomass-derived Oxygenates into Unsaturated Hydrocarbons by $\mathrm{MoO}_{3}$ Using Low $\mathrm{H}_{2}$ Pressures. Energy Environ. Sci. 2013, 6 (6), 1732-1738.

(24) Prasomsri, T.; Shetty, M.; Murugappan, K.; Roman-Leshkov, Y. Insights into The Catalytic Activity and Surface Modification of $\mathrm{MoO}_{3}$ during the Hydrodeoxygenation of Lignin-derived Model 
Compounds into Aromatic Hydrocarbons under Low Hydrogen Pressures. Energy Environ. Sci. 2014, 7 (8), 2660-2669.

(25) Lari, G. M.; Pastore, G.; Haus, M.; Ding, Y.; Papadokonstantakis, S.; Mondelli, C.; Pérez-Ramírez, J. Environmental and Economical Perspectives of a Glycerol Biorefinery. Energy Environ. Sci. 2018, 11 (5), 1012-1029.

(26) Yang, F.; Hanna, M. A.; Sun, R. Value-Added Uses for Crude Glycerol - a Byproduct of Biodiesel Production. Biotechnol. Biofuels 2012, 5, 13-13.

(27) Quispe, C. A. G.; Coronado, C. J. R.; Carvalho, J. A., Jr. Glycerol: Production, Consumption, Prices, Characterization and New Trends in Combustion. Renewable Sustainable Energy Rev. 2013, 27, 475-493.

(28) Lari, G. M.; Chen, Z.; Mondelli, C.; Pérez-Ramírez, J. Bifunctional Hierarchical Zeolite-Supported Silver Catalysts for the Conversion of Glycerol to Allyl Alcohol. ChemCatChem 2017, 9 (12), 2195-2202.

(29) Lari, G. M.; Pastore, G.; Mondelli, C.; Pérez-Ramírez, J. Towards Sustainable Manufacture of Epichlorohydrin from Glycerol Using Hydrotalcite-Derived Basic Oxides. Green Chem. 2018, 20 (1), $148-159$.

(30) Lari, G. M.; de Moura, A. B.; Weimann, L.; Mitchell, S.; Mondelli, C.; Pérez-Ramírez, J. Design of a Technical Mg-Al mixed Oxide Catalyst for the Continuous Manufacture of Glycerol Carbonate. J. Mater. Chem. A 2017, 5 (31), 16200-16211.

(31) Lari, G. M.; Mondelli, C.; Pérez-Ramírez, J. Gas-Phase Oxidation of Glycerol to Dihydroxyacetone over Tailored Iron Zeolites. ACS Catal. 2015, 5 (3), 1453-1461.

(32) Morales, M.; Dapsens, P. Y.; Giovinazzo, I.; Witte, J.; Mondelli, C.; Papadokonstantakis, S.; Hungerbühler, K.; Pérez-Ramírez, J. Environmental and Economic Assessment of Lactic Acid Production from Glycerol Using Cascade Bio-and Chemocatalysis. Energy Environ. Sci. 2015, 8 (2), 558-567.

(33) Lari, G. M.; Mondelli, C.; Papadokonstantakis, S.; Morales, M.; Hungerbühler, K.; Pérez-Ramírez, J. Environmental and Economic Assessment of Glycerol Oxidation to Dihydroxyacetone over Technical Iron Zeolite Catalysts. Reaction Chemistry \& Engineering 2016, 1 (1), 106-118.

(34) Werpy, T.; Petersen, G. Top Value Added Chemicals from Biomass; National Renewable Energy Laboratory, U.S. Department of Energy, 2004.

(35) Thurmond, W. Biodiesel 2020: Global Market Survey, Feedstock Trends and Forecasts; Emerging Markets Online, 2008. https:// docplayer.net/43198174-Biodiesel-2020-global-market-surveyfeedstock-trends-and-forecasts.html (accessed November 2018).

(36) Calamur, N.; Carrera, M. Propylene. In Kirk-Othmer Encyclopedia of Chemical Technology; John Wiley \& Sons, Inc., 2000.

(37) Carr, C. North American Propylene Supply Study; IHS Chemical, 2013.

(38) Peplow, M. How Fracking is Upending the Chemical Industry. Nature 2017, 550 (7674), 26.

(39) Yu, L.; Yuan, J.; Zhang, Q.; Liu, Y.-M.; He, H.-Y.; Fan, K.-N.; Cao, Y. Propylene from Renewable Resources: Catalytic Conversion of Glycerol into Propylene. ChemSusChem 2014, 7 (3), 743-747.

(40) Sousa Fadigas, J. C.; Gambetta, R.; Araujo Mota, C. J.; Conceicao Goncalves, V. L. D. Preparation of Heterogeneous Catalysts Used in Selective Hydrogenation of Glycerin to Propylene and Hydrogenation Process. U.S. Patent US20110184216A1, 2011.

(41) Mota, C. J. A; Gonçalves, V. L. C; Mellizo, J. E.; Rocco, A. M.; Fadigas, J. C.; Gambetta, R. Green Propene through the Selective Hydrogenolysis of Glycerol over Supported Iron-Molybdenum Catalyst: The Original History. J. Mol. Catal. A: Chem. 2016, 422, 158.

(42) Zacharopoulou, V.; Vasiliadou, E. S.; Lemonidou, A. A. OneStep Propylene Formation From Bio-Glycerol over Molybdena-based Catalysts. Green Chem. 2015, 17 (2), 903-912.

(43) Zacharopoulou, V.; Vasiliadou, E. S.; Lemonidou, A. A. Exploring the Reaction Pathways of Bioglycerol Hydrodeoxygenation to Propene over Molybdena-Based Catalysts. ChemSusChem 2018, 11, 264-275.

(44) Moberg, D. R.; Thibodeau, T. J.; Amar, F. G.; Frederick, B. G. Mechanism of Hydrodeoxygenation of Acrolein on a Cluster Model of $\mathrm{MoO}_{3}$. J. Phys. Chem. C 2010, 114 (32), 13782-13795.

(45) Mei, D.; Karim, A. M.; Wang, Y. Density Functional Theory Study of Acetaldehyde Hydrodeoxygenation on $\mathrm{MoO}_{3}$. J. Phys. Chem. C 2011, 115 (16), 8155-8164.

(46) Shetty, M.; Buesser, B.; Roman-Leshkov, Y.; Green, W. H. Computational Investigation on Hydrodeoxygenation (HDO) of Acetone to Propylene on $\alpha-\mathrm{MoO}_{3}(010)$ Surface. J. Phys. Chem. C 2017, 121 (33), 17848-17855.

(47) Lutfalla, S.; Shapovalov, V.; Bell, A. T. Calibration of the DFT/ GGA+U Method for Determination of Reduction Energies for Transition and Rare Earth Metal Oxides of Ti, V, Mo, and Ce. J. Chem. Theory Comput. 2011, 7 (7), 2218-2223.

(48) Getsoian, A. B.; Bell, A. T. The Influence of Functionals on Density Functional Theory Calculations of the Properties of Reducible Transition Metal Oxide Catalysts. J. Phys. Chem. C 2013, 117 (48), 25562-25578.

(49) Capdevila-Cortada, M.; Łodziana, Z.; López, N. Performance of DFT $+\mathrm{U}$ Approaches in the Study of Catalytic Materials. ACS Catal. 2016, 6 (12), 8370-8379.

(50) Rellán-Piñeiro, M.; López, N. One Oxygen Vacancy, Two Charge States: Characterization of Reduced $\alpha-\mathrm{MoO}_{3}(010)$ through Theoretical Methods. J. Phys. Chem. Lett. 2018, 9, 2568-2573.

(51) Kresse, G.; Furthmueller, J. Efficient Iterative Schemes for $a b$ initio Total-Energy Calculations Using a Plane-Wave Basis Set. Phys. Rev. B: Condens. Matter Mater. Phys. 1996, 54, 11169-11186.

(52) Kresse, G.; Furthmuller, J. Efficiency of ab-initio Total Energy Calculations for Metals and Semiconductors Using a Plane-Wave Basis Set. Comput. Mater. Sci. 1996, 6, 15-50.

(53) Perdew, J. P.; Burke, K.; Ernzerhof, M. Generalized Gradient Approximation Made Simple. Phys. Rev. Lett. 1996, 77, 3865-3868.

(54) Grimme, S. Semiempirical GGA-type Density Functional Constructed with a Long-range Dispersion Correction. J. Comput. Chem. 2006, 27, 1787-1799.

(55) Kresse, G.; Joubert, D. From Ultrasoft Pseudopotentials to the Projector Augmented-Wave Method. Phys. Rev. B: Condens. Matter Mater. Phys. 1999, 59, 1758-1775.

(56) Dudarev, S. L.; Botton, G. A.; Savrasov, S. Y.; Humphreys, C. J.; Sutton, A. P. Electron-energy-loss Spectra and the Structural Stability of Nickel Oxide: An LSDA+U Study. Phys. Rev. B: Condens. Matter Mater. Phys. 1998, 57 (3), 1505-1509.

(57) Garcia-Ratés, M.; López, N. Multigrid-Based Methodology for Implicit Solvation Models in Periodic DFT. J. Chem. Theory Comput. 2016, 12 (3), 1331-1341.

(58) Garcia-Ratés, M.; García-Muelas, R.; López, N. Solvation Effects on Methanol Decomposition on $\operatorname{Pd}(111), \operatorname{Pt}(111)$, and $\mathrm{Ru}(0001)$. J. Phys. Chem. C 2017, 121 (25), 13803-13809.

(59) Scanlon, D. O.; Watson, G. W.; Payne, D. J.; Atkinson, G. R.; Egdell, R. G.; Law, D. S. L. Theoretical and Experimental Study of the Electronic Structures of $\mathrm{MoO}_{3}$ and $\mathrm{MoO}_{2}$. J. Phys. Chem. C 2010, 114 (10), 4636-4645.

(60) Magnéli, A.; Andersson, G.; Blomberg, B.; Kihlborg, L. Identification of Molybdenum and Tungsten Oxides by X-Ray Powder Patterns. Anal. Chem. 1952, 24 (12), 1998-2000.

(61) Rellán-Piñeiro, M.; López, N. The Active Molybdenum Oxide Phase in the Methanol Oxidation to Formaldehyde (Formox Process): A DFT Study. ChemSusChem 2015, 8 (13), 2231-2239.

(62) Choksi, T.; Greeley, J. Partial Oxidation of Methanol on $\mathrm{MoO}_{3}$ (010): A DFT and Microkinetic Study. ACS Catal. 2016, 6 (11), $7260-7277$.

(63) Coquet, R.; Willock, D. J. The (010) Surface of a- $\mathrm{MoO}_{3}$, a DFT + U Study. Phys. Chem. Chem. Phys. 2005, 7 (22), 3819-3828.

(64) Lei, Y. H.; Chen, Z. X. DFT+U Study of Properties of $\mathrm{MoO}_{3}$ and Hydrogen Adsorption on $\mathrm{MoO}_{3}(010)$. J. Phys. Chem. C 2012, 116 (49), 25757-25764. 
(65) Makov, G.; Payne, M. C. Periodic Boundary Conditions in $a b$ initio Calculations. Phys. Rev. B: Condens. Matter Mater. Phys. 1995, 51 (7), 4014-4022.

(66) Henkelman, G.; Uberuaga, B. P.; Jonsson, H. A climbing image nudged elastic band method for finding saddle points and minimum energy paths. J. Chem. Phys. 2000, 113, 9901-9904.

(67) Henkelman, G.; Jonsson, H. Improved Tangent Estimate in the Nudged Elastic Band Method for Finding Finimum Energy Paths and Saddle Points. J. Chem. Phys. 2000, 113, 9978-9985.

(68) Henkelman, G.; Jónsson, H. A Dimer Method for Finding Saddle Points on High Dimensional Potential Surfaces Using only First Derivatives. J. Chem. Phys. 1999, 111 (15), 7010-7022.

(69) Heyden, A.; Bell, A. T.; Keil, F. J. Efficient Methods for Finding Transition States in Chemical Reactions: Comparison of Improved Dimer Method and Partitioned Rational Function Optimization Method. J. Chem. Phys. 2005, 123 (22), 224101.

(70) Álvarez-Moreno, M.; de Graaf, C.; López, N.; Maseras, F.; Poblet, J. M.; Bo, C. Managing the Computational Chemistry Big Data Problem: The ioChem-BD Platform. J. Chem. Inf. Model. 2015, 55 (1), 95-103.

(71) Rellán-Piñeiro, M.; López, N. Data Set for: A coupled Density Functional Theory-Microkinetic modeling on the hydrodeoxiygenation of glycerol to propylene on $\mathrm{MoO}_{3}$. DOI: $10.19061 /$ iochem-bd$1-81$.

(72) Chorkendorff, I.; Niemantsverdriet, J. W. Concepts of Modern Catalysis and Kinetics; John Wiley \& Sons, 2003.

(73) Eyring, H. Statistical Mechanical Treatment of the Activated Complex in Chemical Reactions. J. Chem. Phys. 1935, 3, 107-15.

(74) Evans, M. G.; Polanyi, M. Application of the Transition-State Method to the Calculation of Reaction velocities, Especially in Solution. Trans. Faraday Soc. 1935, 31, 875-94.

(75) Maple 13; Maplesoft, a division of Waterloo Maple, Inc., Waterloo, Ontario, 2009.

(76) Teschner, D.; Novell-Leruth, G.; Farra, R.; Knop-Gericke, A.; Schlögl, R.; Szentmiklósi, L.; Hevia, M. G.; Soerijanto, H.; Schomäcker, R.; Pérez-Ramírez, J.; López, N. In Situ Surface Coverage Analysis of $\mathrm{RuO}_{2}$-Catalysed $\mathrm{HCl}$ Oxidation Reveals the Entropic Origin of Compensation in Heterogeneous Catalysis. Nat. Chem. 2012, 4, 739.

(77) Li, Q.; García-Muelas, R.; López, N. Microkinetics of Alcohol Reforming for $\mathrm{H}_{2}$ Production from a FAIR Density Functional Theory Database. Nat. Commun. 2018, 9 (1), 526.

(78) Frei, M. S.; Capdevila-Cortada, M.; García-Muelas, R.; Mondelli, C.; López, N.; Stewart, J. A.; Curulla Ferré, D.; PérezRamírez, J. Mechanism and Microkinetics of Methanol Synthesis via $\mathrm{CO}_{2}$ Hydrogenation on Indium Oxide. J. Catal. 2018, 361, 313-321. 